\title{
Thermal Model Approach to Multisector Three-Phase Electrical Machines
}

\author{
Hengliang Zhang, Paolo Giangrande, Senior Member, IEEE, Giacomo Sala, Zeyuan Xu, Wei \\ Hua, Senior Member, IEEE, Vincenzo Madonna, Member, IEEE, David Gerada, and Chris \\ Gerada, Senior Member, IEEE
}

\begin{abstract}
Multisector machines reveal a high fault-tolerant capability, since failure events can be isolated by de-energizing the faulty sector while the healthy ones contribute in delivering the required power. This paper is focused on the thermal analysis of multisector three-phase machines in healthy and faulty operations. Firstly, a 3D lumped parameter thermal network (LPTN) of a single sector is developed and fine-tuned against experimental data, through a genetic algorithm for identifying the uncertain parameters. According to the operating conditions, the varying housing surface temperature affects the heat exchanged to the ambient. Hence, an analytical formula is proposed to adjust the natural convection coefficient value depending on the operating condition. Then, the 3D-LPTN, modeling the whole machine, is built aiming at investigating the thermal behavior during faulty conditions. Finally, the complete 3D-LPTN is employed for predicting the machine thermal performance under several faulty conditions. Furthermore, the current overload experienced by the healthy sector (in order to keep the same torque level as during the pre-fault operation) is determined, in accordance with the magnet wire thermal class. The effectiveness of the 3D-LPTN in predicting the temperature is experimentally demonstrated.
\end{abstract}

Index Terms-Lumped parameter thermal network, multiphase machine, fault-tolerant machine, multisector machine.

Manuscript received July 30, 2019; revised December 01, 2019, and January 20, 2020; accepted February 15, 2020. This work was supported in part by the National Science Fund for Distinguished Young Scholars under Grant 51825701, in part by the Key R\&D Program of Jiangsu Province under Grant BE2019073, and in part by the Scientific Research Foundation of Graduate School of Southeast University under Grant YBJJ1834. (Corresponding author: Wei Hua.)

Hengliang Zhang and Wei Hua are with the School of Electrical Engineering, Southeast University, Nanjing 210096, China (e-mail: zhanghl2019@163.com; huawei1978@seu.edu.cn).

P. Giangrande, Zeyuan Xu, V. Madonna, D. Gerada and C. Gerada are with the University of Nottingham, Nottingham NG7 2RD, U.K. (e-mail:

Zeyuan.Xu@nottingham.ac.uk;

Vincenzo.Madonna1@nottingham.ac.uk;

David.Gerada@nottingham.ac.uk; Chris.Gerada@nottingham.ac.uk).

G. Sala is with the University of Bologna, 40136 Bologna, Italy (e-mail: g.sala@unibo.it).

\section{INTRODUCTION}

$\mathrm{D}$ UE to the intrinsic features such as fault tolerance, low torque ripple, and power splitting, multiphase machines are attracting a lot of research attention [1]-[3]. These advantages make multiphase drives an interesting solution for high power systems, such as ship propellers, turbo compressors, hybrid aircrafts and wind generators [4]-[7]. In the last decade, the research on multiphase machines has been focused on the electromagnetic aspects, including the machine design, modeling, and control [2]-[9]. Multisector machines are a particular typology of multi three-phase machines, where each three-phase winding is placed in a different area of the stator, namely its sector [10], [11]. It results that each three-phase winding is galvanically insulated and less magnetic coupled with the others. Therefore, if each winding is powered by an independent converter the multisector machines feature an enhanced fault-tolerance capability. Although the thermal analysis on multiphase machines has been addressed in the existing literature [12]-[14], it is still difficult to find technical papers reporting the thermal behavior of multisector machines under faulted conditions.

Since the thermal limit of electrical machines directly affects their power density, efficiency and reliability, the thermal analysis of electrical machines has become an increasingly important research topic in the past decades [15]. Due to the advantage of being fast to compute, the lumped parameter thermal network (LPTN) is one of the most popular methods used for thermal analysis of all types of electrical machines [16]. In [17], an LTPN is built to calculate the transient temperature of induction machines with a totally enclosed fan cooled (TEFC) design. For fractional-slot concentrated winding (FSCW) permanent magnet (PM) machines employed in traction applications, the thermal benefits due to the proposed back-iron extension are assessed by using an LPTN in [18]. The authors of [19] derive an LPTN for the stator winding with a good accuracy and a low computation cost. A 3D-LPTN which requires a relatively low computational effort is introduced for the thermal analysis of a low-speed high-trust actuator in [20].

However, the LPTN approach features some demerits as well. The most significant problem is that it is impossible to accurately determine some critical parameters of the LPTN, e.g. the equivalent thermal conductivity of winding, the interference gap between stator and housing, the heat transfer coefficient 
due to convection, etc. Some distinguished works on the determination of these critical parameters have been reported in [21]-[26]. The equivalent thermal conductivity of electrical winding is estimated in [22]-[24]. In [25], [26], some empirical formulae are derived to assess the convective heat transfer in electrical machines.

Although the LPTN can be established based on these empirical values, it still contains significant uncertainties, which may cause errors between simulations and experimental tests. To reduce the level of uncertainty in the estimation of the LPTN parameters, some calibration methods have been developed. By using a particle swarm optimization routine, the thermal conductivity of stator winding in an AC machine is calibrated based on the experimental data from thermal tests performed on a stator-winding motorette in [27]. With the help of Matlab SIMSCAPE and Simulink Design Optimization, the critical convection coefficients in a water-cooled electrical machine are tuned on the basis of the tests on a stator sector in [28]. Nevertheless, the use of motorettes is less appropriate for multisector machines, since it does not provide a complete picture of the actual thermal behavior.

The modularity featured by multisector machines allows to isolate the faulty sector by opening it (i.e. the faulty sector is de energized), in case a failure occurs either within the winding sector or the power converter feeding it. To compensate the output torque shortage arising from the sector opening (i.e. asymmetric-sector operation), the current flowing through the remaining sectors must be increased. However, such post fault strategy leads to overload operation of the healthy sectors, which might result in winding over heating. This peculiar working condition requires a detailed thermal analysis of the whole multisector machine in order to avoid the shortening of the insulation lifetime. To predict the thermal stress on the insulation, the thermal behavior is investigated by means of a fine-tuned 3D-LPTN, which is able to account for different asymmetric-sector operations of the multisector machine at hand. Apart from temperature prediction, the purposely built 3D-LPTN is employed for determining the maximum allowable current in the healthy sectors with respect to the magnet wire thermal class. The temperature prediction provided by the 3D-LPTN is experimentally validated.

\section{MACHINE TOPOLOGY}

The multisector machine under study is a 21-slot 6-pole $(21 \mathrm{~s} / 6 \mathrm{p})$ surface permanent magnet (SPM) motor, as shown in Fig. 1, where the power converters feeding each three-phase winding set are also reported. Its main parameters are listed in Table I, while the key characteristic of the PM material as function of the temperature are given in Table II. A detailed investigation on this machine topology was presented in [29].

The machine is divided into 3 independent sectors and each sector is equipped with a three-phase winding (marked as $\mathrm{A} 1-\mathrm{B} 1-\mathrm{C} 1$ or A2-B2-C2 or A3-B3-C3), which is supplied by its independent power source. The choice of a triple three-phase surfaced mounted PMs machine is supported by the need of increasing both reliability and availability of the whole electric drive. However, different topologies of electrical machines, e.g. the dual stator winding induction machines (DSWIM) [30], [31] and the brushless synchronous generators [32], might also feature a multisector configuration.

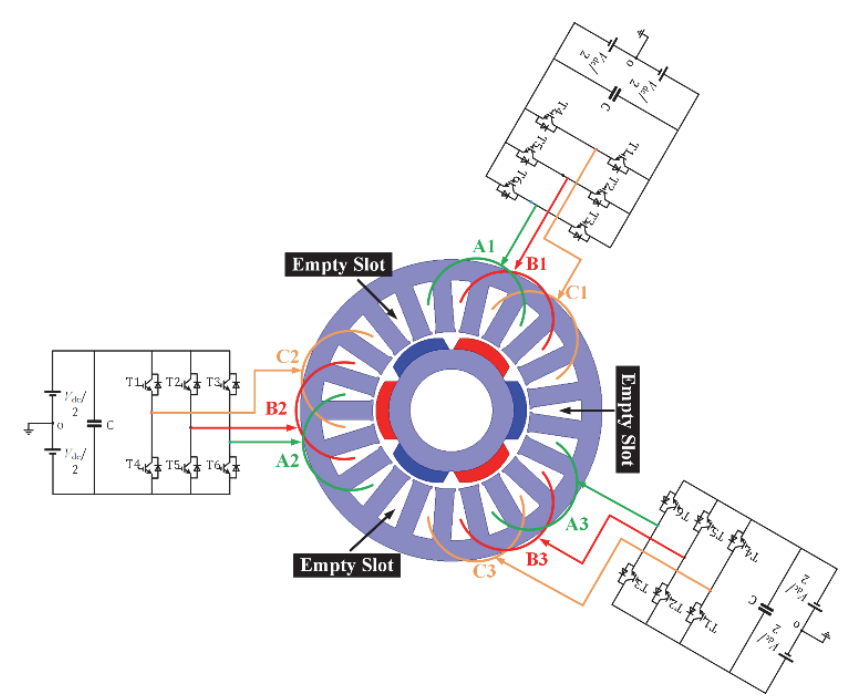

Fig. 1. Cross-sectional view of the triple three-phase sectored machine.

During the section division, the whole machine should be averagely and symmetrically divided. Therefore, the greatest common divisor between the stator slots number and the rotor poles number is considered for the investigated machine.

$$
N_{\text {sec }}=G . C . D .\left\{N_{s}, 2 p\right\}
$$

where $N_{s}$ is the number of stator slot, $p$ is the pole-pair number and $N_{s e c}$ is the number of the sectors. In PMs machines, the parameter $p$ represents half of the PMs number, while for the machines with salient rotors the parameter $p$ can be determined according to the fundamental working field harmonic, which can be pointed by the field modulation theory [33], [34].

In the multisector $21 \mathrm{~s} / 6 \mathrm{p}$ SPM machine, the adjacent sectors are separated with each other by an empty slot that might also be thermally exploited to improve the thermal management of the multisector machine. Nonetheless, this possibility will not be addressed in the present paper. Further, the presence of the empty slots makes the magnetic mutual coupling between windings belonging to different sectors negligible compared to the one between phases of the same sector.

Table I

Key Parameters of the Triple Three-Phase Sectored Machine

\begin{tabular}{cc|cc}
\hline \hline Parameter & Value & Parameter & Value \\
\hline Rated power & $1.2 \mathrm{~kW}$ & DC voltage & $72 \mathrm{~V}$ \\
Stator outer radius & $47.5 \mathrm{~mm}$ & Slot number & 21 \\
Stator inner radius & $24.74 \mathrm{~mm}$ & Pole number & 6 \\
Air gap length & $0.95 \mathrm{~mm}$ & Rated speed & $3000 \mathrm{r} / \mathrm{min}$ \\
Stator Yoke thickness & $6.5 \mathrm{~mm}$ & Rated current & $7 \mathrm{~A}(\mathrm{RMS})$ \\
Stator tooth width & $5.7 \mathrm{~mm}$ & PM material & NdFeB \\
Turn number per phase & 22 & Silicon steel sheet & M250-35A \\
\hline \hline
\end{tabular}


Table II

Characteristic of the PM Material

\begin{tabular}{ccc}
\hline \hline Temperature & Remanence & Coercivity \\
\hline $20{ }^{\circ} \mathrm{C}$ & $1.24 \mathrm{~T}$ & $-958 \mathrm{KA} / \mathrm{m}$ \\
$60{ }^{\circ} \mathrm{C}$ & $1.20 \mathrm{~T}$ & $-930 \mathrm{KA} / \mathrm{m}$ \\
$100^{\circ} \mathrm{C}$ & $1.16 \mathrm{~T}$ & $-895 \mathrm{KA} / \mathrm{m}$ \\
$140^{\circ} \mathrm{C}$ & $1.11 \mathrm{~T}$ & $-856 \mathrm{KA} / \mathrm{m}$ \\
$180{ }^{\circ} \mathrm{C}$ & $1.05 \mathrm{~T}$ & $-805 \mathrm{KA} / \mathrm{m}$ \\
\hline
\end{tabular}

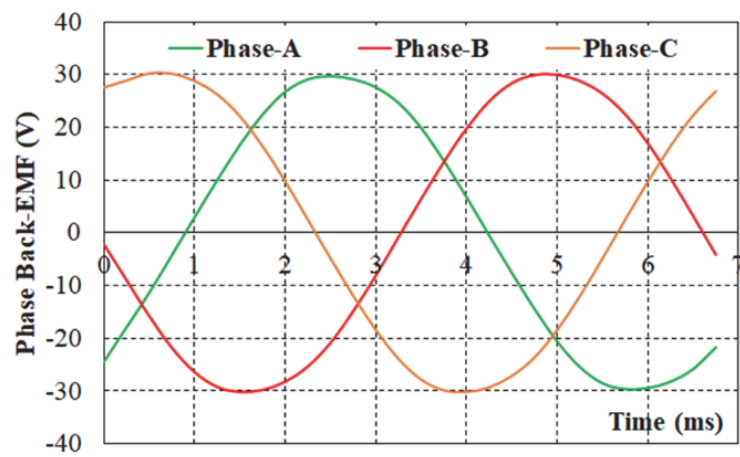

Fig. 2. FEA-calculated phase back-EMF waveforms of the multisector three-phase machine at $3000 \mathrm{r} / \mathrm{min}$.

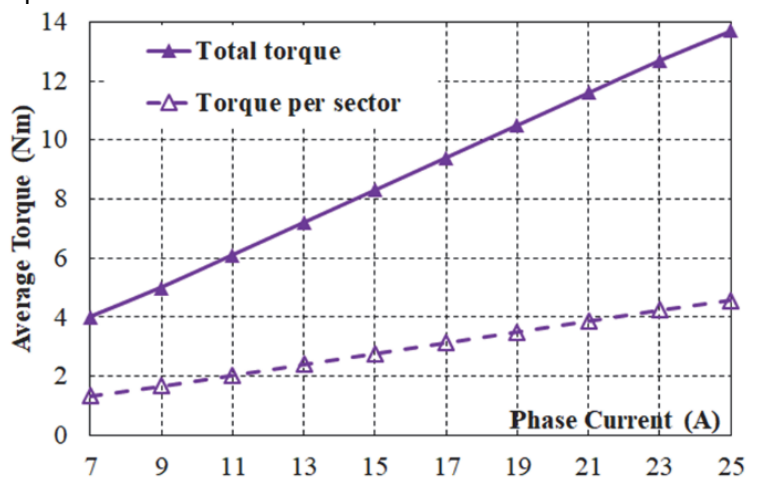

Fig. 3. FEA-calculated torque-current curves of the proposed machine.

By using the 2D-finite element analysis (FEA) method, the phase back-EMFs are obtained as illustrated in Fig. 2. Due to symmetry reasons and figure clarity, only the back-EMFs induced in one sector at rated speed are provided in the figure. In addition, Fig. 3 shows the torque-current characteristic of the proposed machine, which is the reference of phase current during postfault operations. The control strategy of the designed triple-sector three-phase machine has been discussed in [29]. The following parts will be focused on the thermal model approach.

\section{Single Sector Thermal Modelling}

In this section, a 3D-LPTN representing only a single sector of the presented machine is developed to predict the cooling performances under various operating conditions. A genetic algorithm is applied to the 3D-LPTN, whose purpose is to reduce the prediction error caused by the random selection of the critical parameters. Further, the natural convection heat transfer coefficients for different operating conditions are predicted based on the fine-tuned 3D-LPTN and analytical formulae. The LPTN predicted thermal performances are evaluated using experimental data under healthy conditions.

\section{A. The LPTN Method}

The LPTN has been proved as an effective tool for thermal analysis of electrical machines [35]. For each node in the LPTN, a heat transfer equation can be expressed by:

$$
P_{i}-\sum_{j \neq i}\left(\theta_{i}-\theta_{j}\right) g_{i j}=C_{i} \frac{d \theta_{i}}{d t}
$$

where $P_{i}$ is the heat generated in $i^{\text {th }}$ node, $\theta_{i}$ and $\theta_{j}$ are the temperatures of the $i^{\text {th }}$ and $j^{\text {th }}$ nodes respectively, $C_{i}$ is the thermal capacitance in $i^{\text {th }}$ node and $g_{i j}$ is the thermal conductance between the $i^{\text {th }}$ and $j^{\text {th }}$ nodes.

For a thermal steady-state case, the temperature variation against time is zero and the above heat transfer equation (2) can be simplified in a matrix format as follows:

$$
\left[\begin{array}{ccc}
\sum_{j \neq 1} g_{1 j} & \cdots & -g_{1 N} \\
\vdots & \ddots & \vdots \\
-g_{N 1} & \cdots & \sum_{j \neq N} g_{N j}
\end{array}\right]\left[\begin{array}{c}
\theta_{1} \\
\vdots \\
\theta_{N}
\end{array}\right]=\left[\begin{array}{c}
P_{1} \\
\vdots \\
P_{N}
\end{array}\right]
$$

If the thermal transient behaviors of the machine cooling are considered, (2) can be expressed and solved in a matrix format as follows:

$$
\left[\begin{array}{ccc}
\sum_{j \neq 1} g_{1 j} & \cdots & -g_{1 N} \\
\vdots & \ddots & \vdots \\
-g_{N 1} & \cdots & \sum_{j \neq N} g_{N j}
\end{array}\right]\left[\begin{array}{c}
\theta_{1} \\
\vdots \\
\theta_{N}
\end{array}\right]+\left[\begin{array}{c}
C_{i} \frac{d \theta_{i}}{d t} \\
\vdots \\
C_{N} \frac{d \theta_{N}}{d t}
\end{array}\right]=\left[\begin{array}{c}
P_{1} \\
\vdots \\
P_{N}
\end{array}\right]
$$

From (3) and (4), the accurate machine loss, the accurate thermal conductance matrix, and the accurate thermal capacity are essential conditions for accurate temperature prediction.

The loss of permanent-magnet machines includes the core loss, the eddy current loss, the copper loss, the mechanical loss, and the stray loss. By using FEA and analytical methods, the core loss, the eddy current loss, and the copper loss can be calculated if the accurate operation temperature is set. However, these losses are sensitive to the temperature, which means a strong coupling exists between the loss and temperature. The iterative calculation is necessary to predict the temperature of electrical machines. The accurate thermal conductance matrix is the foundation for achieving a correct convergence. Furthermore, the determination of the mechanical loss and the stray loss relies on the experimental measurements.

The thermal conductance matrix is made up of three types of conductance, including conduction, convection, and radiation. It is worth mentioning that the radiation heat transfer is omitted in the 3D-LPTN, since its contribution is low for the case study under investigation. The thermal conductance can be calculated according to the geometrical information and corresponding thermal coefficient which are insensitive to the temperature except the natural convection coefficient.

The thermal capacities only affect the transient temperature prediction. They can be calculated according to the mass and the specific heat capacity which can be accurately assigned based on the datasheets of the corresponding materials.

From the above analysis, the machine losses are strongly coupled with the temperature in thermal analysis while the 
thermal conductance matrix is not. Furthermore, the accurate thermal conductance matrix is the foundation for a correct calibration of the machine loss. Hence, the thermal conductance matrix should be firstly fine-tuned by conducting a single thermal test. Then the fine-tuned thermal matrix can be used to adjust the loss model, which can help the motor designer to find the correct direction to improve the thermal behavior of the machine.

\section{B. Layout of the $3 D-L P T N$}

Observing the thermal conductance matrix of the thermal network, it is found that the thermal network can be studied by means of graph theory using a weighted graph, where each thermal conductance ( $g_{i j}$ in Fig. 4(a) or $G_{i j}$ in Fig. 4(b)) is the weight of the corresponding line in the graph, and the thermal conductance matrix is the adjacent matrix of this graph. Based on the graph theory, the information carried by the thermal conductance matrix can be divided into two parts which are the layout information, and the thermal conductance information.

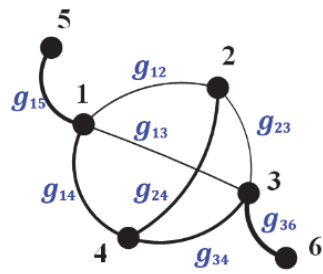

(a)

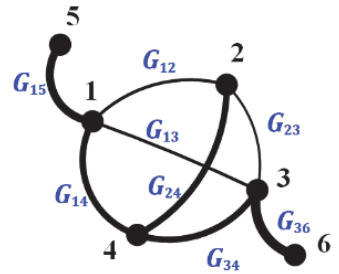

(b)

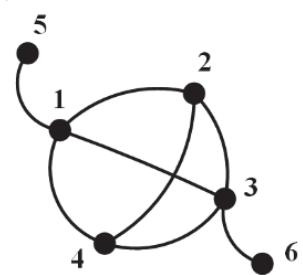

(c)

Fig. 4. Example of graph theory: (a) Weighted graph for a 5-kW 18s/6p SPM machine, (b) Weighted graph for a 10-kW 18s/6p SPM machine and (c) Un-weighted graph

Figs. 4 (a) and (b) show two typical weighted graphs that might be used for modelling the thermal networks of two electrical machines, which are characterized by the same slot/pole combination (i.e. topology), but different rated power (i.e. geometry), e.g. a $5-\mathrm{kW} 18 \mathrm{~s} / 6 \mathrm{p}$ SPM machine and a $10-\mathrm{kW}$ $18 \mathrm{~s} / 6 \mathrm{p}$ SPM machine respectively. It is possible to note that the two graphs feature the same layout, since the corresponding machines share an identical topology, while their parameter values differ due to the distinct geometry. The common layout allows to 'translate' these two weighted graphs into a generic un-weighted graph, as depicted in Fig. 4 (c).

Hence, the un-weighted graph carries the information regarding the machine topology, which has general validity, while the weight of the connection between nodes is univocally defined by the machine geometry and power rating, resulting in a weighted graph. Therefore, the research on thermal conductance matrix can be divided into two parts, which are the LPTN layout, and the determination of thermal conductance. The LPTN layout is an un-weighted graph, which is easy to accurately determined according to the machine topology. The machines with the same topology feature the same LPTN layout.

Considering the $21 \mathrm{~s} / 6 \mathrm{p}$ triple three-phase sectored SPM machine introduced in Section II, the 3D-LPTN corresponding to half single sector (i.e. $1 / 6$ of the whole machine) is developed in terms of un-weighted thermal network. In Fig. 5, the 2D view of the implemented 3D-LPTN is illustrated, where red and blue lines represent the heat transfer due to conduction and convection respectively. For completeness, the development of the 3 slots LPTN along the third dimension is shown in Fig. 6 and three slices along the axial direction of the machine $(z$ direction) are modelled.

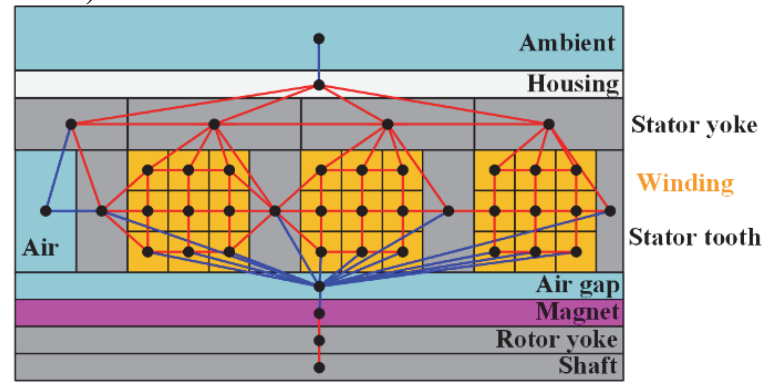

Fig. 5. 2D view of the un-weighted thermal network modelling half single sector of the 21s/6p SPM machine.

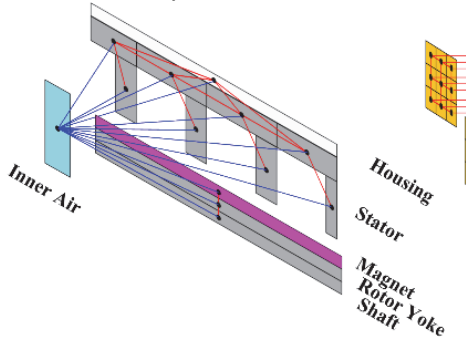

(a)

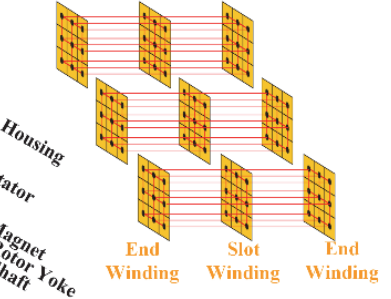

(b)
Fig. 6. Development in the z-direction of the un-weighted thermal network: (a) stator/rotor modelling and (b) winding modelling

\section{Fine-Tuning of the Critical Parameters}

After determining the layout of the 3D-LPTN of the $21 \mathrm{~s} / 6 \mathrm{p}$ SPM machine, the corresponding thermal conductance should be determined to get a complete thermal conductance matrix. In this step, some critical parameters are challenging to be assigned and will affect the accuracy of the LPTN predicted results [36]. These critical parameters are as follows.

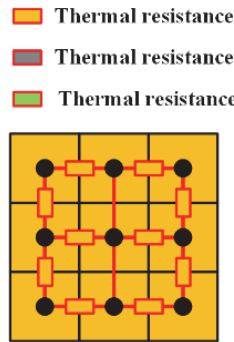

(a)

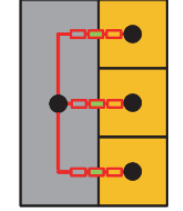

(b)

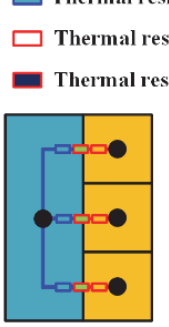

(c) (d)

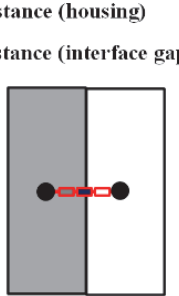

Fig. 7. Four types of critical thermal resistances. (a) Thermal resistance of winding. (b) Thermal resistance between winding and stator lamination. (c) Thermal resistance between winding and inner air. (d) Thermal resistance between housing and stator. 
The first critical parameter is the equivalent transversal thermal conductivity of the winding. In electrical machines, the winding consists of at least four types of materials including the copper, the enamel of the wire, the insulation varnish, and potentially some air. Hence, the equivalent transversal thermal conductivity of the winding must be determined in order to calculate the thermal resistance of the winding in the LTPN model as shown in Fig. 7(a). However, to the best of the authors' knowledge, there is not in the existing literature an accurate model to predict the equivalent conductivity of the four-phase materials yet. The determination of the equivalent thermal conductivity of the winding still relies heavily on experimental data and experience. It should be noted that the "manufacturing goodness" has significant influence on the equivalent thermal conductivity of the winding [23]. However, it is impossible to theoretically assess the "manufacturing goodness."

The second critical parameter is the equivalent thermal conductivity and the equivalent thickness of the slot liner. The slot liner is located between the stator lamination and the winding. Hence, the thermal resistance of the slot liner should be considered when calculating the thermal resistance between the stator lamination and the winding, as shown in Fig. 7 (b). However, it is impossible to accurately predict the interface gaps among the slot liner, the stator lamination, and the winding. The thermal conductivity of the slot liner is not easy to determine as well. Hence, the equivalent thickness and the equivalent thermal conductivity are introduced to represent the influence of these parameters in the thermal model.

The convection heat transfer coefficient is another critical parameter. The convection heat transfer is an important phenomenon in electrical machines. For instance, the convection thermal resistance should be taken into account when calculate the thermal resistance between the winding and the inner air as shown in Fig. 7 (c). However, the corresponding convection heat transfer coefficient is hard to determine.

In addition, the interface gap exists between the machine housing and the stator as shown in Fig. 7(d). Since this gap is significantly affected by the manufacturing procedure, it is quite difficult to accurately determine it in the LPTN model.

Moreover, the length of ending winding also has an important influence on the thermal analysis. This parameter is determined by the manufacturing, the machine dimension, and the wire specifications.

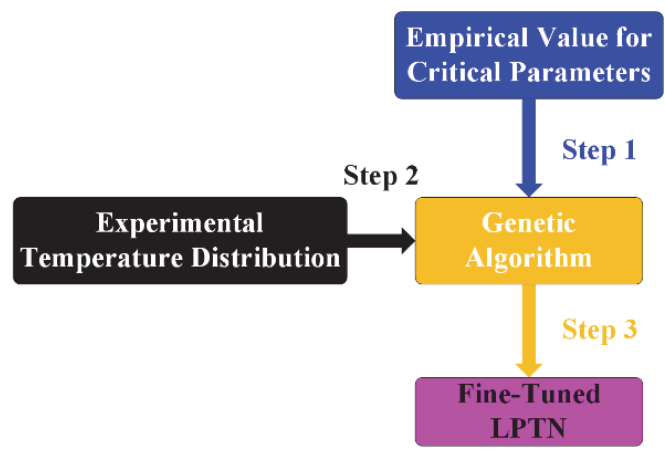

Fig. 8. Flowchart of the fine-tuning procedure.
In order to conduct an accurate thermal analysis, all of these parameters should be fine-tuned. The following part shows a detailed fine-tuning process, which is based on a genetic algorithm and consists of three steps, as highlighted in Fig. 8.

Step 1: The critical parameters are identified and their initial value is set to be within suitable ranges as suggested by the available literature [22]-[27]. Once this stage is completed, the LPTN is preliminary weighted with the first generation of critical parameters.

For the $21 \mathrm{~s} / 6 \mathrm{p}$ triple three-phase sectored SPM machine, the selected critical parameters include the equivalent transversal thermal conductivity of the winding, equivalent thermal conductivity of slot liner, equivalent thickness of slot liner, equivalent interface gap between stator and housing, natural convection heat transfer coefficient of machine housing surface, heat transfer coefficient of air inside machine and average end winding length. In Table III, these critical parameter values tuned by the genetic algorithm are listed and it is worth to note that they are within the ranges expected from the existing literatures.

Table III Critical Parameters Values

\begin{tabular}{ccc}
\hline \hline Uncertain Parameter & $\begin{array}{c}\text { Empirical } \\
\text { Value }\end{array}$ & $\begin{array}{c}\text { Final LPTN } \\
\text { Value }\end{array}$ \\
\hline Equivalent transversal thermal & $0.1 \sim 0.5$ & $0.29 \mathrm{~W} / \mathrm{m} / \mathrm{K}$ \\
conductivity of winding & $\mathrm{W} / \mathrm{m} / \mathrm{K}$ & \\
Equivalent thermal conductivity of slot & $0.03 \sim 0.2$ & $0.18 \mathrm{~W} / \mathrm{m} / \mathrm{K}$ \\
liner & $\mathrm{W} / \mathrm{m} / \mathrm{K}$ & $0.26 \mathrm{~mm}$ \\
Equivalent thickness of slot liner & $0.25 \sim 0.5 \mathrm{~mm}$ & $0.026 \mathrm{~mm}$ \\
Interface gap between stator and housing & $0.01 \sim 0.1 \mathrm{~mm}$ & $8.9 \mathrm{~W} / \mathrm{m}^{2} / \mathrm{K}$ \\
Surface natural convection coefficient & $2 \sim 15 \mathrm{~W} / \mathrm{m}^{2} / \mathrm{K}$ & $8.1 \mathrm{~W} / \mathrm{m}^{2} / \mathrm{K}$ \\
Heat transfer coefficient of air inside & $2 \sim 15 \mathrm{~W} / \mathrm{m}^{2} / \mathrm{K}$ & 1.33 \\
machine & $1.3 \sim 1.6$ & \\
End winding length coefficient & & \\
\hline \hline
\end{tabular}

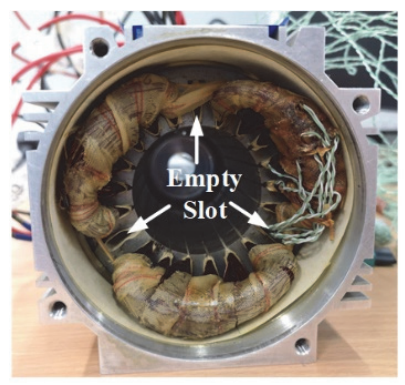

(a)

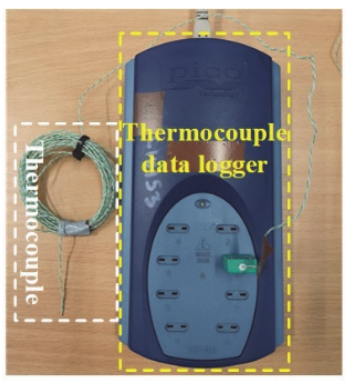

(b)
Fig. 9. Equipment employed during the test campaign. (a) Prototyped machine stator. (b) Thermocouple and data logger.

Step 2: Using the equipment shown in Fig. 9, thermal tests are conducted using the actual machine to obtain the temperature distributions until steady-state is reached. The collected temperature profiles are then used as benchmark to validate the genetic algorithm optimized LPTN-predicted values.

A DC current is injected into the static 21s/6p SPM machine to simplify the machine losses to the copper loss only. Since the tested machine is cooled by the natural air convection, the injected current density is set to limited to $5 \mathrm{~A} / \mathrm{mm}^{2}$ maximum. The tested machine is located within a large enclosure 
environment to ensure no force air flow around the machine of natural convection condition. The rotor is not rotating and no forced air flow within the machine end region. Two endcaps cover the front and rear of the tested machine.

Step 3: Starting from LPTN which uses the first generation of critical parameters selected from the available literature, the genetic algorithm produces a new population of critical parameters through crossover and mutation [37]. In particular, the future generations of critical parameters are generated to minimize the mismatches between predicted temperatures and experimental data, according to a function $E$ defined by (5).

$$
E=\sum\left|T_{i}-T_{i}^{*}\right|
$$

where $T_{i}{ }^{*}$ is the measured temperature of $i^{\text {th }}$ node, while $T_{i}$ is the LPTN-estimated temperature of $i^{\text {th }}$ node. The tournament-based selection method is applied to select the 3D-LPTN with the lowest $E$, which represents the fine-tuned 3D-LPTN. The genetic algorithm calculates 32 generations and the population size of each generation is made of 1024 individuals. Fig. 10 reports both the average and lowest values of the function $E$ for each generation. For the $32^{\text {nd }}$ generation, the average value is less than $7{ }^{\circ} \mathrm{C}$, whilst $6{ }^{\circ} \mathrm{C}$ is the lowest value.

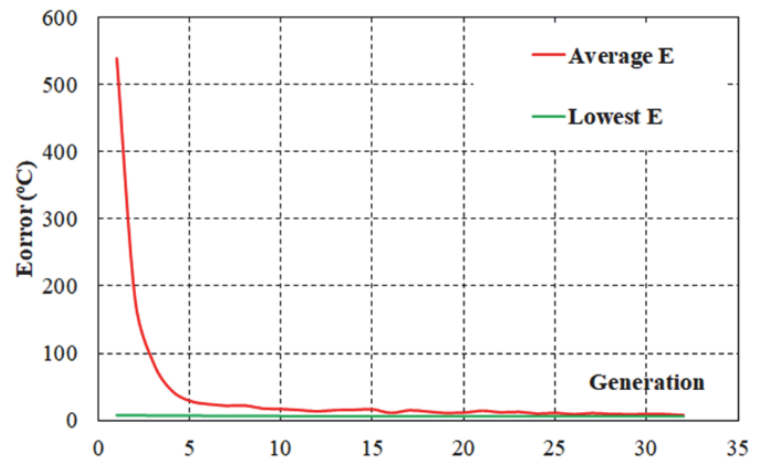

Fig. 10. Trend of the function $E(5)$ at each critical parameter set generation: average (red line) and lowest (green line) values.

Table IV

Comparison between Measured and LPTN-Predicted Steady-State Temperatures

\begin{tabular}{ccc}
\hline \hline Location & Measured Value & Final LPTN Value \\
\hline Stator yoke 1 & $91.7{ }^{\circ} \mathrm{C}$ & $91.6^{\circ} \mathrm{C}$ \\
Stator yoke 2 & $92.9^{\circ} \mathrm{C}$ & $91.8^{\circ} \mathrm{C}$ \\
Empty slot & $92.8^{\circ} \mathrm{C}$ & $92.1{ }^{\circ} \mathrm{C}$ \\
Slot I & $93.1{ }^{\circ} \mathrm{C}$ & $94.9{ }^{\circ} \mathrm{C}$ \\
Slot II & $96.2^{\circ} \mathrm{C}$ & $95.4^{\circ} \mathrm{C}$ \\
Slot III & $95.1^{\circ} \mathrm{C}$ & $95.3^{\circ} \mathrm{C}$ \\
Internal air & $90{ }^{\circ} \mathrm{C}$ & $90{ }^{\circ} \mathrm{C}$ \\
End winding & $98.2^{\circ} \mathrm{C}$ & $99.5^{\circ} \mathrm{C}$ \\
\hline \hline
\end{tabular}

A comparison between measured and LPTN predicted temperatures is given in Table IV, for a thermal steady condition, where the temperatures in 8 nodes are evaluated. According to Table IV results, the end winding is confirmed to be the machine hot spot by both LPTN and experimental data. A good agreement is achieved between LPTN predicted values and measured temperatures, and this proves the effectiveness of the LPTN fine tuning procedure through genetic algorithm. It is worth to mention that the predicted slot temperatures refer to the slot central node, while "Slot I" is the nearest to the empty slot.

The transient thermal behaviors of the machine can also be predicted using the fine-tuned 3D-LPTN developed for this machine. Direct comparisons of the temperature rising profiles at several locations of the machine, predicted by the LPTN against the experimental measured temperature data at the corresponding positions are shown in Figs 11-13. As can be seen from the results, the predicted temperature rising followed the machine temperature changes very well. The LPTN fine-tuning procedure can be considered successfully completed and provided the best parameters for the LPTN. Hence, exploiting the sector geometrical symmetry, the single sector LPTN is obtained (i.e. $1 / 3$ of the whole machine), as illustrated in Fig. 14 where only the 2D view is provided, since the LPTN extension does not affect the slice number in the axial direction.

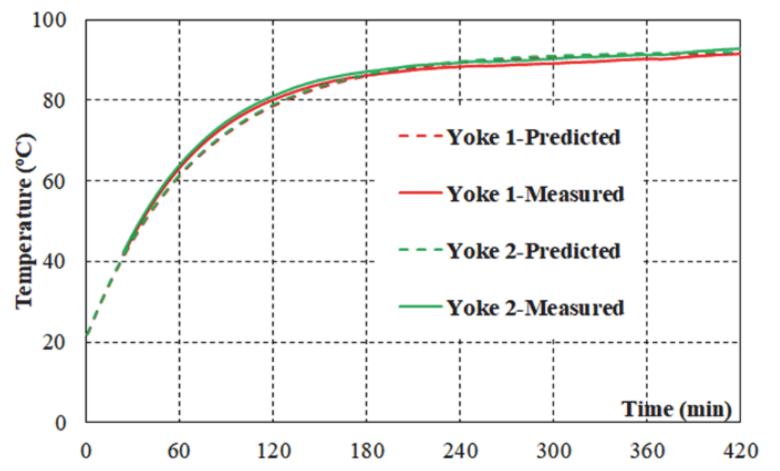

Fig. 11. Stator yoke temperature profiles with $5 \mathrm{~A} / \mathrm{mm}^{2}$ current density: LPTN predicted (dashed lines) and measured (continuous lines).

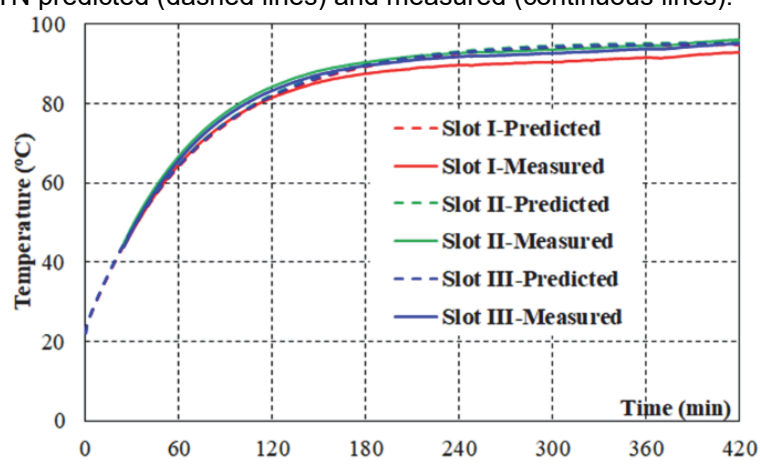

Fig. 12. Slots temperature profiles with $5 \mathrm{~A} / \mathrm{mm}^{2}$ current density: LPTN predicted (dashed lines) and measured (continuous lines).

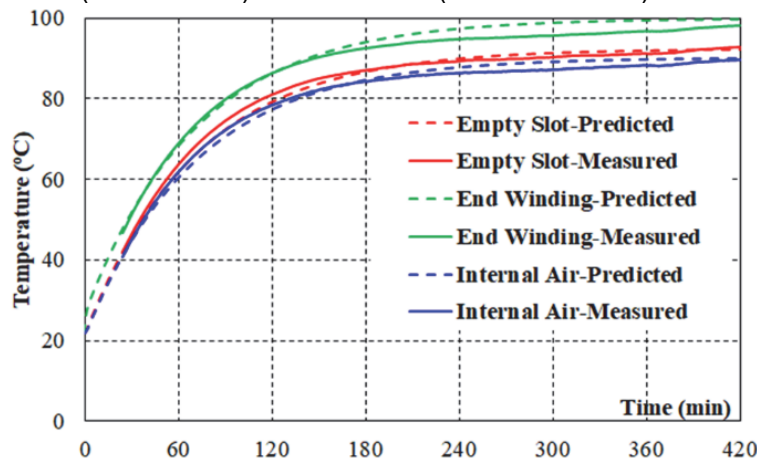

Fig. 13. Temperature profiles with $5 \mathrm{~A} / \mathrm{mm}^{2}$ current density for end winding, empty slot and internal air. 


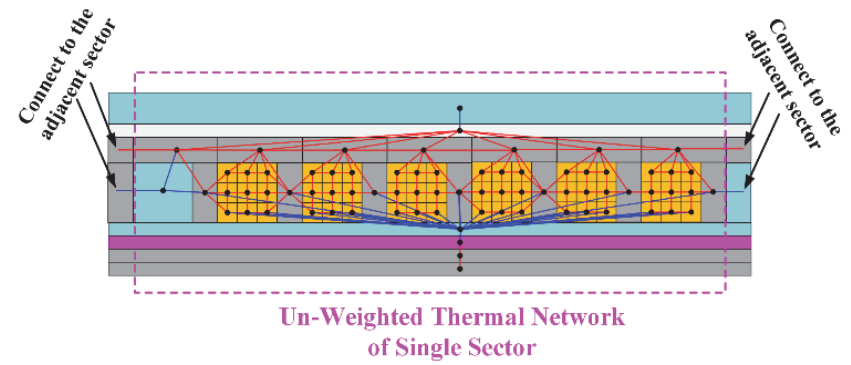

Fig. 14. 2D view of the un-weighted thermal network modelling a single sector of the $21 \mathrm{~s} / 6 \mathrm{p}$ SPM machine.

\section{Correction of the Surface Natural Convection Heat Transfer Coefficient}

As the machine is cooled by natural convection, the surface natural convection heat transfer coefficient $h_{n c}$ plays an important role in the accuracy of the LPTN. In general, the surface natural convection heat transfer coefficient $h_{n c}$ can be calculated by the following dimensionless numbers [38].

$$
\begin{gathered}
N u=C_{o 1} h_{n c} \\
N u=C_{o 2} R a^{\frac{1}{4}} \\
R a=C_{o 3}\left(T_{s}-T_{a m}\right)
\end{gathered}
$$

where $N u$ is the Nusselt number, $R a$ is the Rayleigh number, $T_{s}$ is the surface temperature, $T_{a m}$ is the ambient temperature, and $C_{o 1}, C_{o 2}$, and $C_{03}$ are three coefficients determined by the environment and housing geometry. In case of a machine working in the same environment, $C_{o 1}, C_{o 2}$, and $C_{o 3}$ are three constant values if the temperature dependences of air properties are ignored which is reasonable as the temperature variation around of the machine is not significant for various operating conditions.

By combining and rearranging equations (6)-(8), it is found that $h_{n c}$ is affected by the surface temperature of the machine housing. Assuming two generic load conditions marked with $A$ and $B$, the corresponding temperatures on the housing surface can be identified as $T_{s}$ and $T_{s}{ }^{*}$ respectively. These surface temperatures lead to two values of surface natural convection heat transfer coefficient, i.e. $h_{n c}$ and $h_{n c}{ }^{*}$, and their ratio is expressed by (9), whose validity is restricted by the assumption of constant environment.

$$
\frac{h_{n c}}{h_{n c}^{*}}=\left(\frac{T_{s}-T_{a m}}{T_{s}^{*}-T_{a m}}\right)^{\frac{1}{4}}
$$

Through the fine-tuning procedure introduced in Part B, the surface natural convection coefficient has been accurately determined based on an experimental test, where the three sectors are simultaneously fed with $5 \mathrm{~A} / \mathrm{mm}^{2}$. Under this test condition, the housing surface temperature is equal to $89.8^{\circ} \mathrm{C}$, whereas $8.9 \mathrm{~W} / \mathrm{m}^{2} / \mathrm{K}$ is the obtained natural convection coefficient. On this basis, the surface natural convection heat transfer coefficient for different operating conditions can be predicted by using the iteration shown in Fig. 15.

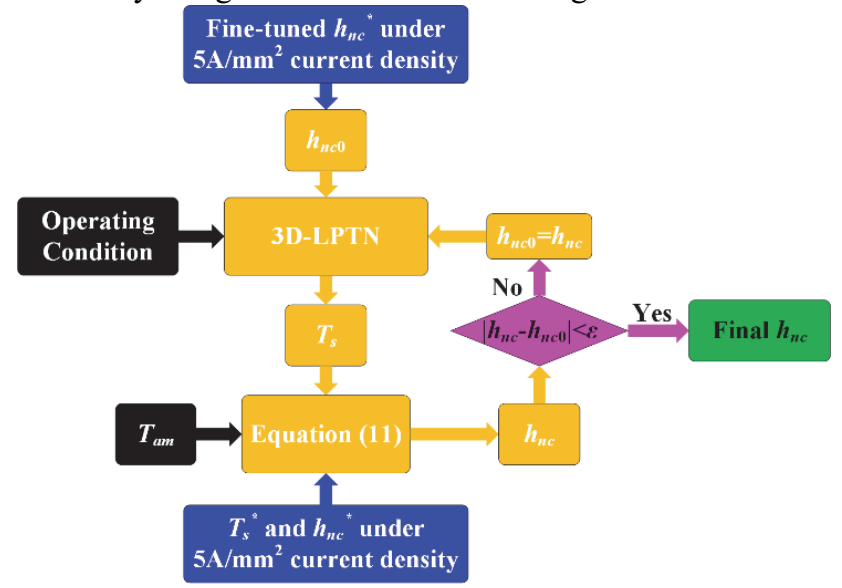

Fig. 15. The iteration for predicting the surface natural convection heat transfer coefficient.

Further, the natural surface convection heat transfer coefficient of the 3D-LPTN can be experimentally assessed based on (10).

$$
h_{n c}=\frac{p_{\text {loss }}}{A_{s}\left(T_{s}-T_{a m}\right)}
$$

where $p_{\text {loss }}$ is the measured loss, $T_{s}$ is the measured temperature of machine housing, $T_{a m}$ is the ambient temperature, and $A_{s}$ is the surface area of the machine housing which is calculated by means of the 3D-LPTN.

Considering several operating conditions, the surface natural convection coefficient of the presented machine is predicted and measured. The obtained results are summarized in Fig. 16, where the impact of the temperature of the machine housing on the natural convection coefficient is evident. Good agreements are achieved between the prediction and measurement.

Therefore, the 3D-LPTN modelling the machine is updated by including (9), which allows to account for the phenomena highlighted in Fig. 16. Hence, the complete fine-tuned 3D-LPTN has been derived for investigating the machine thermal performance during asymmetric operation of the machine sectors.

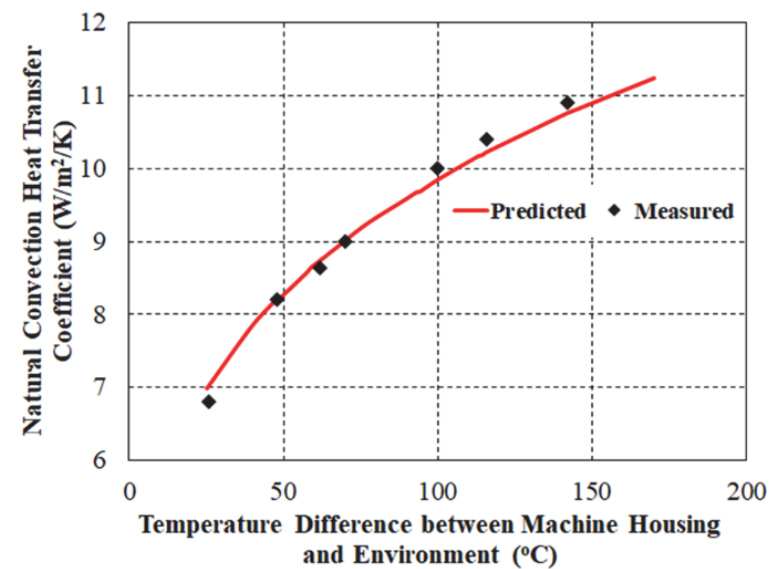

Fig. 16. Natural convection coefficient versus temperature difference between the machine housing and the environment. 


\section{WhOle MACHINE THERMAL MOdELLING}

The single-sector fine-tuned LPTN determined in the previous section can be further extended in order to model the whole multisector machine, to predict the thermal performances under various faulty conditions, where the machine is under unbalanced loads of the 3 sectors. This operation can be avoided for the case when three sectors work under symmetric load conditions (i.e. the three three-phase windings are supplied with identical current values), since the expected thermal behavior is the same for all sectors and the thermal analysis can be performed on a single sector (faster and simplest choice). Conversely, when the three sectors are fed with different current values (i.e. asymmetric load conditions), the LPTN developed for the whole machine can be applied, despite the higher computational timing is required for solving it.

The latter mentioned case mirrors the operating conditions occurring during a power sharing operation of the multi three-phase machine [39], [40], and when in response to a power converter or winding failure, the faulty sector is de energized. During post-fault operations, the heat source distribution becomes asymmetric and boundary conditions of the whole machine LPTN model will be different, as shown in Fig. 17.

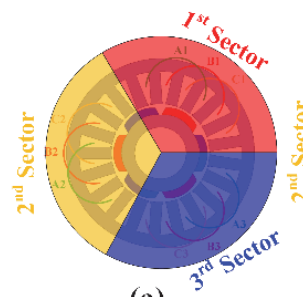

(a)

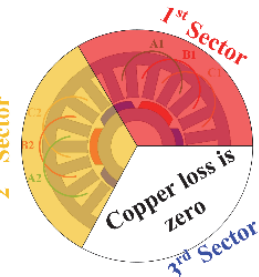

(b)

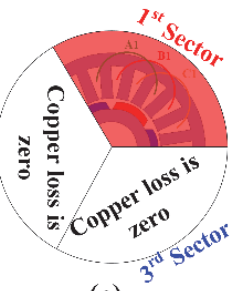

(c)
Fig. 17. Copper loss distribution under different operating conditions. (a) Healthy operation. (b) Single failure operation. (c) Double failure operation.

A 536-node 3D-LPTN for the whole machine is developed based on the previous 95-node LPTN for the half sector of machine in order to simulate the whole machine under faulty conditions. The same methodologies and critical parameters determined by the half-sector LPTN are applied to the whole machine model, with the only exception of the surface natural convection coefficient which can be calculated by using the iteration shown in Fig. 15. Hence, the achievement of the completed weighted 3D-LPTN is quite straightforward and it does not demand a second round of fine tuning, which would be significantly more time consuming due to the elevated number of thermal nodes.

\section{Thermal Performance During Faulty OPERATIONS}

As previously mentioned, multisector machines feature a high fault-tolerant capability and any failure taking place on the power lane (either on the sector winding or feeding power electronic) can be isolated by de-energizing the faulty winding. The detailed discussion is as follows.

When the failure occurs at the converter level, de-energizing the faulty converter can effectively prevent the failure propagation.

When the failure occurs at the motor level, the connection between the faulty sector winding and its power converter is open by using the de-energizing approach, which prevents the failure propagation to the converter level. If the short-circuit fault occurs, although the faulty sector winding is not anymore supplied by the power converter, short-circuit currents circulate within the faulty winding, due to the back-emf induced by the PM. This risk is mitigated by the fault-tolerant design of the machine, i.e. in case of winding short-circuit the currents are limited by the machine impedance. Further, in this case the proposed LPTN is used for predicting the maximum operating time under fault condition.

It should be noted that the back-EMF distortion of the short circuit current will remain in both the healthy and faulty phases, resulting in control difficulties for the inverters of the remaining healthy phases. Hence in this paper the fault is assumed to be an open phase fault.

Due to the failure occurrence, the following scenarios are foreseen:

1. Mode I - after the failure detection, the faulty sector is de energized (no contribution to the torque production is given) and the current in the remaining sectors is kept unchanged (i.e. no post fault compensation strategy is adopted). Such approach on one hand prevents the failure propagation, but on the other hand, the overall torque developed by the multisector machine drops and the system performance is compromised.

2. Mode II - following the faulty sector de energization, the current in the healthy sectors is increased (i.e. overload condition) in order to keep the same generated torque, as in the pre fault operation. Such method allows to avoid the performance derating of the multisector machine.

Further, it is worth to underline that the machine under study is characterized by three sectors, therefore its availability is also guaranteed in case two sectors are affected by failure.

Considering the described scenarios, the thermal behavior of the multisector machine has been evaluated using the complete fine-tuned 3D-LPTN. In particular, each thermal simulation is divided in three stages and their time duration has been selected in order to reach the thermal steady state.

- Healthy operation (i.e. 1st stage): during the timespan from 0 to 4 hours, the three sectors are simultaneously active and they are fed with a phase current of 7 A per winding sector, which allows to deliver the rated torque at the motor shaft.

- Single failure operation (i.e. 2 nd stage): from 4 to 8 hours, one sector is opened, as result of a failure detection, and the current in the healthy sector windings is increased from $7 \mathrm{~A}$ to $11 \mathrm{~A}$, in order to produce the rated torque (i.e. $4 \mathrm{Nm}$ ).

- Double failure operation (i.e. 3rd stage): for the next 11.5 minutes (i.e. from 8 to 8.19 hours), another sector is de energized and the rated torque is only developed by one sector, whose winding is supplied with $22.5 \mathrm{~A}$. 
The phase current values related to the above stages are listed in Table V. Also, a direct comparison of end winding temperature profiles predicted by the developed 3D-LPTN with the experimental measured temperature profiles at different machine failure operation modes is made and the results are shown in Fig. 18.

Table V

Phase Current Value for Developing the Rated Torque at Different Failure Modes

\begin{tabular}{cccc}
\hline \hline Loading Condition & $\mathbf{1}^{\text {st }}$ Sector & $\mathbf{2}^{\text {nd }}$ Sector & $\mathbf{3}^{\text {rd }}$ Sector \\
\hline $\begin{array}{c}\text { Healthy operation } \\
\text { Single failure } \\
\text { operation } \\
\begin{array}{c}\text { Double failure } \\
\text { operation }\end{array}\end{array}$ & $7 \mathrm{~A}$ & $7 \mathrm{~A}$ & $7 \mathrm{~A}$ \\
\hline \hline
\end{tabular}

For healthy condition, the maximum difference between the predicted and measured temperatures is $2.4{ }^{\circ} \mathrm{C}$ which corresponds to a relative error of $3.3 \%$. Under the single failure operation, the maximum absolute error is $3.74{ }^{\circ} \mathrm{C}$ which corresponds to a relative error of $2.8 \%$. For the double failure operation, the maximum absolute error is $6{ }^{\circ} \mathrm{C}$, and the corresponding relative error is $3.4 \%$. According to the prediction, the machine can produce the rated torque for 11.5 minutes under double failure operation, while the measured result is 10 minutes. Overall, good agreements have been achieved between the simulations and experimental tests.

The unbalanced magnetic force of the machine under healthy and faulty conditions are compared in Fig. 19. The machine under healthy condition features no unbalanced magnetic force, while the machine features the heaviest unbalanced magnetic force under double failure operation, which will shorten the lifespan of the bearings. The maximum unbalanced magnetic force under double failure operation is $154 \mathrm{~N}$.

Furthermore, the proposed model can also be used to predict the temperatures under short-circuit faults. The short-circuit faults can result in very high fault current (depending on the design), which may cause the extremely high temperatures in faulty points. To avoid more dangerous consequences, the maximum postfault operation time is the most important index in the analysis of short-circuit faults.

To assess the dangerous level of the short-circuit fault, the maximum acceptable temperature $T_{\max }$ is set according to the thermal class of the insulation. Then, the temperature prediction under the short-circuit faults can be addressed as follows:

1. The short-current is calculated and assigned to the faulty phases. The theoretical "steady-state" temperature under this current is calculated and compared with the maximum acceptable temperature $T_{\max }$.

2. If the "steady-state" temperature is higher than the maximum acceptable temperature $T_{\max }$, the short-circuit windings burn after long-time operation, which is of course dangerous. For this condition, the proposed model can be used to predict the maximum postfault operation time according to the transient temperatures of short-circuit windings.

This feature of the developed thermal model is evaluated by considering a single-phase short-circuit fault occurring inside the machine, whose rotor is rotating at $3000 \mathrm{r} / \mathrm{min}$. Knowing that the phase back-EMF of the investigated 21-slot/6-pole machine is equal to $21.6 \mathrm{~V}$ (RMS value) at $3000 \mathrm{r} / \mathrm{min}$, while its phase inductance and resistance are $0.78 \mathrm{mH}$ and $80 \mathrm{~m} \Omega$ (at $100^{\circ} \mathrm{C}$ ) respectively; the single-phase short-circuit current results equal to $29.2 \mathrm{~A}$ at $3000 \mathrm{r} / \mathrm{min}$ [41]. Although the short-circuit fault is promptly detected and the gate pulses to the faulty winding sector are removed (i.e. the current in healthy phases of the faulty sector becomes zero), the $29.2 \mathrm{~A}$ current is still circulating through the machine's faulty phase (i.e. the fault is fed by the back-EMF even if the power lane is de-energized). Under these conditions, the developed thermal model is used to determine the maximum postfault operation time. In particular, the resulting short-circuit current is given as input to the thermal model and it is found that the short-circuit phase winding will achieve $200^{\circ} \mathrm{C}$ (i.e. magnet wire thermal class) in 720 seconds, which is the maximum operation time after a single-phase short-circuit fault at $3000 \mathrm{r} / \mathrm{min}$.

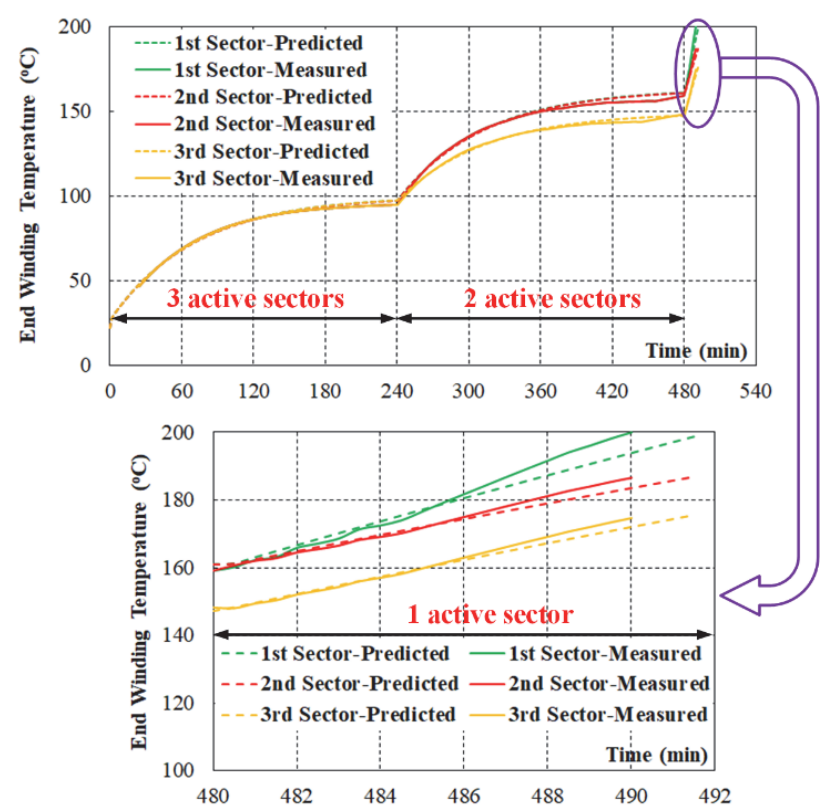

Fig. 18. Comparison between measured and LPTN predicted winding temperatures under healthy, single failure and double failure operations.

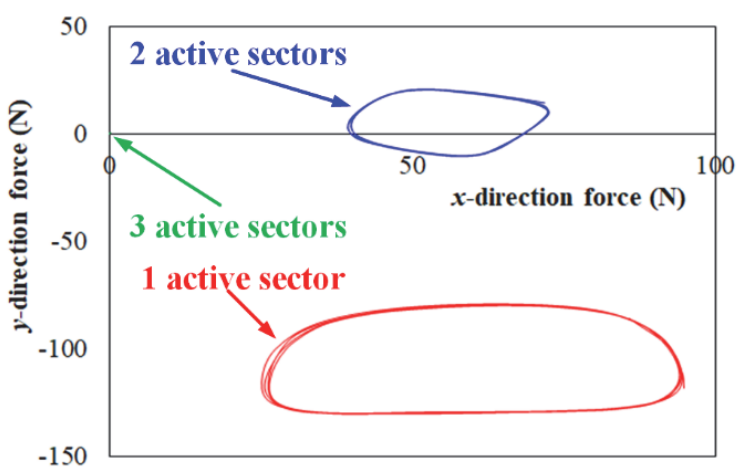

Fig. 19. Unbalanced magnetic force of the rotor under healthy, single failure and double failure operations. 


\section{CONCLUSIONS}

This paper presented a detailed thermal analysis of a fault-tolerant multisector machine, which was performed through a $3 \mathrm{D}-\mathrm{LPTN}$ which models the whole machine. The developed LPTN was fine-tuned against experimental data for determining its critical parameters and an analytical formula is deduced to recalibrate the natural convection coefficient according to operating conditions. A genetic algorithm was used during the fine-tuning procedure. The accuracy of the developed 3D-LPTN was assessed in healthy and faulty conditions, with a maximum estimation error of $3.4 \%$ in the worst-case scenario. The fault-tolerant capability of the designed machine was experimentally proved and its operational boundaries were experimentally defined in case of both single and double failure. For a single failure, the machine is still able to develop the rated torque without compromising the insulation lifetime (hot-spot temperature below the magnet wire thermal class). In case of double failure, the machine can produce the rated torque for about 10 minutes before the winding temperature exceeds the limitation, under the condition which features the highest unbalanced magnetic force. At the next step of the presented work, the empty slots will be thermally exploited to improve the thermal performance of the presented machine, while making careful consideration to aspects such as the space utilization, losses, and the electromagnetic design goals of the multi-sector machine design.

\section{REFERENCES}

[1] E. Levi, "Multiphase electric machines for variable-speed applications," IEEE Trans. Ind. Electron., vol. 55, no. 5, pp. 1893-1909, May 2008.

[2] F. Barrero, and M. J. Duran, "Recent advance in the design, modeling, and control of multiphase machines-Part I," IEEE Trans. Ind. Electron., vol. 63, no. 1, pp. 449-458, Jan. 2016.

[3] M. J. Duran, and F. Barrero, "Recent advance in the design, modeling, and control of multiphase machines-Part II," IEEE Trans. Ind. Electron. vol. 63, no. 1, pp. 459-468, Jan. 2016.

[4] J. Dai, S. W. Nam, M. Pande, and G. Esmaeili, "Medium-voltage current-source converter drives for marine propulsion system using a dual-winding synchronous machine," IEEE Trans. Ind. Appl., vol. 50, no. 6, pp. 3971-3976, Nov. 2014.

[5] A. Tessarolo, G. Zocco, and C. Tonello, "Design and testing of a $45 \mathrm{mw}$ 100-hz quadruple-star synchronous motor for a liquefied natural gas turbo-compressor drive," IEEE Trans. Ind. Appl., vol. 47, no. 3, pp 1210-1219, May. 2011.

[6] R. Bojoi, A. Cavagnino, A. Tenconi, and S. Vaschetto, "Control of shaft-line-embedded multiphase starter/generator for aero-engine," IEEE Trans. Ind. Electron., vol. 63, no. 1, pp. 641-652, 2016.

[7] V. Yaramasu, B. Wu, P. C. Sen, S. Kouro, and M. Narimani, "High power wind energy conversion systems: State-of-the-art and emerging technologies," Proc. IEEE, vol. 103, no. 5, pp. 740-788, May. 2015.

[8] I. Zoric, M. Jones, and E. Levi, "Arbitrary power sharing among three-phase winding sets of multiphase machines," IEEE Trans. Ind. Electron., vol. 65, no. 2, pp. 1128-1139, Feb. 2018.

[9] K. Wang, "Effects of harmonics into magnet shape and current of dual three-phase permanent magnet machine on output torque capability," IEEE Trans. Ind. Electron., vol. 65, no. 11, pp. 8758-8767, 2018.

[10] G. Sala, G. Valente, et al., "Space vectors and pseudoinverse matrix methods for the radial force control in bearingless multisector permanent magnet machines," IEEE Trans. Ind. Electron., vol. 65, no. 9, pp. 6912-6922, Sep. 2018

[11] G. Valente, L. Papini, et al., "Radial force control of multisector permanent-magnet machines for vibration suppression," IEEE Trans. Ind. Electron., vol. 65, no. 7, pp. 5395-5405, Jul. 2018.
[12] P. Taras, G. J. Li, et al., "Combined multiphysics model of switched flux PM machines under fault operations," IEEE Trans. Ind. Electron., vol. 66 , no. 9, pp. 6737-6745, Sep. 2019

[13] N. Bianchi, E. Fornasiero, et al., "Thermal analysis of a five-phase motor under faulty operations," IEEE Trans. Ind. Appl., vol. 49, no. 4, pp. 1531-1538, Jul./ Aug. 2013.

[14] M. Popescu, D. Dorrell, et al., "Thermal analysis of duplex three-phase induction motor under fault operating conditions," IEEE Trans. Ind. Appl., vol. 49, no. 4, pp. 1523-1530, Jul./ Aug. 2013.

[15] A. Boglietti, A. Cavagnino, et al., "Evolution and modern approaches for thermal analysis of electrical machines," IEEE Trans. Ind. Electron., vol. 56, no. 3, pp. 871-882, Mar. 2009.

[16] Motor-CAD. [Online]. Available: www.motor-design.com.

[17] P. Mellor, D. Roberts, et al., "Lumped parameter thermal model for electrical machines for TEFC design," Proc. Inst. Elect. Eng. B-Elect. Power Appl., vol 138, no. 5, pp. 205-218, Sep. 1991.

[18] F. Zhang, D. Gerada, et al., "Back-iron extension thermal benefits for electrical machines with concentrated windings," IEEE Trans. Ind. Electron., vol 67, no. 3, pp. 1728-1738, Mar. 2020.

[19] C. Sciascera, P. Giangrande, et al., "Analytical thermal model for fast stator winding temperature prediction," IEEE Trans. Ind. Electron., vol. 64, no. 8, pp. 6116-6126, Aug. 2017.

[20] A. Tessarolo, and C. Bruzzese, "Computationally efficient thermal analysis of a low-speed high-thrust linear electric actuator with a three-dimensional thermal network approach," IEEE Trans. Ind. Electron., vol. 62, no. 3, pp. 1410-1420, Mar. 2015.

[21] A. Boglietti, A. Cavagnino, et al., "Determination of critical parameters in electrical machine thermal models," IEEE Trans. Ind. Appl., vol. 44, no. 4, pp. 1150-1159, Jul./ Aug. 2008.

[22] N. Simpson, R. Wrobel, et al., "Estimation of equivalent thermal parameters of impregnated electrical windings," IEEE Trans. Ind. Appl., vol. 49 , no. 6 , pp. 2505-2515, Nov./ Dec. 2013

[23] A. Boglietti, E. Carpaneto, et al., "Sator winding thermal conductivity evaluation: an industrial production assessment," IEEE Trans. Ind. Appl., vol. 52, no. 5, pp. 3893-3900, Sep./ Oct. 2016.

[24] A. Boglietti, M. Cossale, et al., "Thermal conductivity evaluation of fractional-slot concentrated-winding machines," IEEE Trans. Ind. Appl., vol. 53, no. 3, pp. 2059-2065, May/ June 2017.

[25] D. Staton, and A. Cavagnino, "Convection heat transfer and flow calculations suitable for electrical machines thermal models," IEEE Trans. Ind. Electron., vol. 55, no. 10, pp. 3509-3516, Oct. 2008.

[26] D. Howey, P. Childs, et al., "Air-gap convection in rotating electrical machines," IEEE Trans. Ind. Electron., vol. 59, no. 3, pp. 1367-1375, Mar. 2012.

[27] J. Godbehere, R. Wrobel, et al., "Experimentally calibrated thermal stator modeling of AC machines for short-duty transient operation," IEEE Trans. Ind. Appl., vol. 53, no. 4, pp. 3457-3466, Jul./ Aug. 2017.

[28] V. Madonna, A. Walker, et al., "Improved thermal management and analysis for stator end-windings of electrical machines," IEEE Trans. Ind. Electron., vol. 66, no. 7, pp. 5057-5069, Jul. 2019.

[29] G. Sala, D. Gerada, et al., "Design and control of segmented triple three-phase SPM machines for fault tolerant drives," in 2017 IEEE Workshop on Electrical Machines Design, Control and Diagnosis (WEMDCD), Nottingham, 2017, pp. 63-68.

[30] S. Basak, and C. Chakraborty, "Dual stator winding induction machine: problems, progress, and future scope," IEEE Trans. Ind. Electron., vol. 62, no. 7, pp. 4641-4652, Jul. 2015.

[31] A. Munoz, T. Lipo, "Dual stator winding induction machine drive," IEEE Trans. Ind. Appl., vol. 36, no. 5, pp.1369-1379, Sep. 2000.

[32] C. Chakraborty, S. Basak, Y.T. Rao, "Synchronous generator with embedded brushless synchronous exciter," IEEE Trans. Energy Convers., vol. 34, no. 3, pp. 1242-1254, Sep. 2019.

[33] M. Cheng, P. Han, and W. Hua, "A general airgap field modulation theory for electrical machines," IEEE Trans. Ind. Electron., vol.64, no.8, pp.6063-6074, Aug. 2017.

[34] M. Cheng, H. Wen, et al., "Analysis of airgap field modulation principle of simple salient poles," IEEE Trans. Ind. Electron., vol.66, no.4, pp.2628-2638, Apr. 2019.

[35] T.A. Lipo, Introduction to AC machine design, Wisconsin Power Electronics Research Center, University of Wisconsin-Madison, 2011.

[36] V. Madonna, P. Giangrande, C. Gerada, and M. Galea, "Thermal analysis of fault-tolerant electrical machines for aerospace actuators," IET Electric Power Applications, vol. 13, no. 7, pp. 843-852, Jul. 2019. 
[37] R. L. Haupt, "An introduction to genetic algorithms for electromagnetics," IEEE Antennas Propag. Mag., vol. 37, no. 2, pp. 7-15, Apr. 1995.

[38] Yunus Cengel, Heat transfer, McGraw-Hill, 2002.

[39] G. Sala, M. Mengoni, et al., "Decoupled d-q axes current sharing control of multi three-phase induction machines," IEEE Trans. Ind. Electron. early access. DOI: 10.1109/TIE.2019.2941127.

[40] I. Subotic, O. Dordevic, et al., "Active and reactive power sharing between three-phase winding sets of a multiphase induction machine," IEEE Trans. Energy Convers., vol. 34, no. 3, pp. 1401-1410, Sep. 2019.

[41] N. Bianchi, S. Bolognani, et al., "Strategies for the fault-tolerant current control of a five-phase permanent-magnet motor," IEEE Trans. Ind. Appl., vol. 43, no. 4, pp. 960-970, Jul./ Aug. 2007.

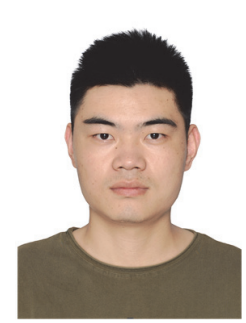

Hengliang Zhang was born in Anhui, China, in 1992. He received the B.Sc. degree in electrica engineering from Southeast University, Nanjing, China, in 2014. He is currently working toward the Ph.D. degree in electrical engineering with the School of Electrical Engineering, Southeast University, Nanjing, China. From 2018 to 2019 he was with the Power Electronics, Machines and Control Group, The University of Nottingham, Nottingham, U.K., as a Joint-Supervised Ph.D. Student. His research interests include the electromagnetic design, and thermal analysis of permanent magnet machines.

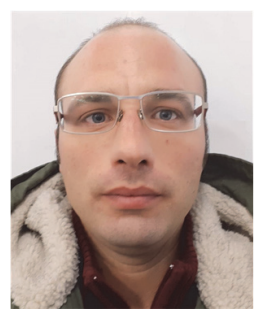

Paolo Giangrande (M'12-SM'19) received the Bachelor's (Hons.) and Master's (Hons.) degrees in electrical engineering at the Politecnico of Bari in 2005 and 2008, respectively. He received his $\mathrm{PhD}$ in electrical engineering at the Politecnico of Bari in 2011.

Since 2012, he was Research Fellow at the University of Nottingham (UK), within the Power Electronics, Machines and Control Group. In 2018, he was appointed Senior Research Fellow and he is currently head of the Accelerated Lifetime Testing Laboratory at the Institute of Aerospace Technology, Nottingham. His main research interests include sensorless control of $A C$ electric drives, design and testing of electromechanical actuators for aerospace, thermal management of high-performance electric drives and lifetime modelling of electrical machines.

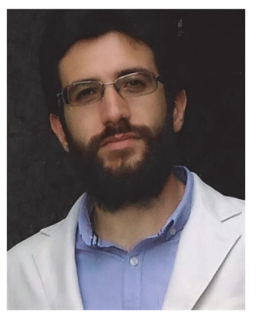

Giacomo Sala was born in Vercelli, Italy, in 1990. $\mathrm{He}$ received the $\mathrm{B}$. Sc. in Power Engineering in 2012 the M. Sc. degree with honors in Electrica Engineering in 2014 and the Ph. D. in Electrical Machines and Drives in 2018 from the University of Bologna, Italy.

He worked as a researcher until 2019 in the Power Electronics, Machines and Control Group, Department of Electrical and Electronic Engineering, The University of Nottingham. He is currently a researcher in the Department of Electrical, Electronic, and Information Engineering "Guglielmo Marconi" - DEI, University of Bologna, Italy. His research interests include design, modelling and control of multiphase electrical machines, fault tolerant controls and fault diagnosis of electrical drives.

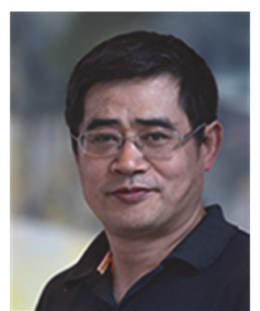

Zeyuan $\mathbf{X u}$ received the Ph.D. degree in mechanical engineering from the University of Manchester, Manchester, U.K., in 2002.

$\mathrm{He}$ subsequently worked as a Research Fellow at UMIST, Brunel University, and University of Nottingham. He is currently a Senior Research Fellow in thermo-mechanical design of high-speed electrical machines within the PEMC group at University of Nottingham, Nottingham, U.K. His main research interests include turbulent thermo-fluid flow, heat transfer enhancement, and thermal management of advanced electrical machines and power electronics.

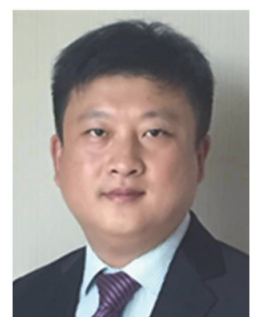

Wei Hua (SM'16) received the B.Sc. and Ph.D. degrees in electrical engineering from Southeast University, Nanjing, China, in 2001 and 2007, respectively. From 2004 to 2005, he was with the Department of Electronics and Electrical Engineering, The University of Sheffield, U.K., as a Joint-Supervised Ph.D. Student.

Since 2007, he has been with Southeast University, where he is currently a Chief Professor of Southeast University and a Distinguished Professor of Jiangsu Province. He has co-authored over 150 technical papers. He holds 50 patents in his areas of interest. His teaching and research interests include design, analysis, and control of electrical machines, especially for PM brushless machines and switching reluctance machines, etc.

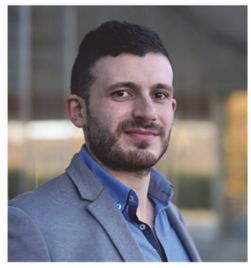

Vincenzo Madonna (M'17) received the Laurea Magistrale degree in Electrical Engineering from the University of Bologna, Italy, in 2016. In the same year he was awarded the prestigious Marie Skłodowska-Curie Fellowship and joined the Institute for Aerospace Technology at the University of Nottingham, UK as a Doctoral Fellow in reliability-oriented design of electrical machines for transportation. Vincenzo is currently a Research Fellow with the Propulsion Futures Beacon of Excellence at the University of Nottingham. His research interests include design, thermal management and reliability assessment of electrical machines. During his three-year $\mathrm{PhD}$ programme, he has authored more than 25 papers, published in various IEEE Transactions, Magazines and conference proceedings.

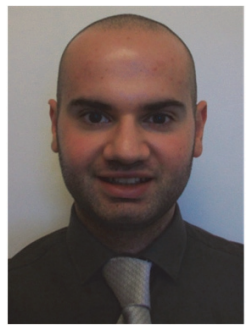

David Gerada received the Ph.D. degree in high-speed electrical machines from the University of Nottingham, Nottingham, UK in 2012.

From 2007-2016 he was with the R\&D Department at Cummins, first as an Electromagnetic Design Engineer (2007-2012), and then as a Senior Electromagnetic Design Engineer and Innovation Leader (2012-2016). At Cummins he pioneered the design and development of high-speed electrical machines, transforming a challenging technology into a reliable one suitable for the transportation market, while establishing industry-wide used metrics for such machinery. In 2016 he joined the University of Nottingham as a Senior Fellow in Electrical Machines, responsible for developing state of the art electrical machines for future transportation which push existing technology boundaries, while propelling the new technologies to higher technology readiness levels (TRL). Dr. Gerada is a Chartered Engineer in the U.K. and a member of the Institution of Engineering and Technology.

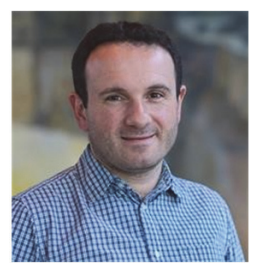

Chris Gerada (SM'12) is an Associate Pro-Vice-Chancellor for Industrial Strategy and Impact and Professor of Electrical Machines. His principal research interest lies in electromagnetic energy conversion in electrical machines and drives, focusing mainly on transport electrification. He has secured over $£ 20 M$ of funding through major industrial, European and UK grants and authored more than 350 referred publications. He received the Ph.D. degree in numerical modelling of electrical machines from The University of Nottingham, Nottingham, U.K., in 2005. He subsequently worked as a Researcher with The University of Nottingham on high-performance electrical drives and on the design and modelling of electromagnetic actuators for aerospace applications. In 2008, he was appointed as a Lecturer in electrical machines; in 2011, as an Associate Professor; and in 2013, as a Professor at The University of Nottingham. He was awarded a Research Chair from the Royal Academy of Engineering in 2013. Prof. Gerada served as an Associate Editor for the IEEE TRANSACTIONS ON INDUSTRY APPLICATIONS and is the past Chair of the IEEE IES Electrical Machines Committee. 